\title{
Processo de Criação da Obra Coreográfica Jezebel
}

Palavras-chave: dança jazz -
processos de criação - coreografia

Palavras-chave: dança jazz
processos de criação - coreografia

\section{Resumo}

O presente estudo tem por objetivo analisar o processo de criação da coreógrafa Anette Lubisco, dando destaque à obra coreográfica Jezebel. O mesmo se caracteriza como uma pesquisa qualitativa com aporte metodológico da história oral, tendo como base a entrevista semiestruturada realizada com a coreógrafa e três bailarinas. Os dados coletados foram transformados em registro histórico em prol da preservação da história da dança jazz. Descrevemos primeiramente o processo de criação da coreógrafa e depois apresentamos e analisamos a proposta coreográfica “Jezebel”.

\section{* Priscila Ramos Gagliardi \\ ** Christiane Gracia Macedo
$* * *$ Aline Nogueira Haas \\ ** Christiane Gracia Macedo
$* * *$ Aline Nogueira Haas}

\begin{abstract}
The aim of this study was to analyze the creating process of the choreographer Anette Lubisco, highlighting the choreography Jezebel. The research is characterized as qualitative with methodological contribution of oral history, based on a semi-structured interview with the choreographer and three dancers. Data were transformed into historical record for the preservation of the jazz dance history. First we describe the choreographer creating process and after we analyze the choreographic "Jezebel”.
\end{abstract}

keywords: jazz dance - creating process choreography

\footnotetext{
* Licenciada em Dança pela Universidade Federal do Rio Grande do Sul. E-mail: pri-ramos@hotmail.com

** Mestre em Ciências do Movimento Humano pela Universidade Federal do Rio Grande do Sul.

*** Professora Adjunto do Curso de Licenciatura em Dança e do Program de Pós-graduação em Ciências do Movimento Humano da Universidade Federal do Rio Grande do Sul.
} 
Este texto tem como objetivo analisar os processos de criação da coreógrafa Anette Lubisco dando ênfase na proposta coreográfica chamada "Jezebel”. Pertencente à segunda geração de professores e coreógrafos do Estado do Rio Grande do Sul (HAAS et al, 2013). A coreógrafa e bailarina Anette Lubisco foi escolhida para este trabalho, por ser uma das precursoras da dança jazz no estado e por ainda estar atuando nos dias de hoje.

Ela iniciou seus estudos na dança por volta de 1977, com 16 anos, quando começou a fazer aulas com uma professora de dança jazz chamada Marília. Logo após, essa professora alugou um espaço na Escola Tony Petzhold, no andar acima do local onde o Ballet Phoenix ${ }^{1}$ ensaiava e realizava suas aulas. Jussara Miranda, professora do Ballet Phoenix, conheceu Anette nessa época e a convidou para fazer algumas aulas junto com o Grupo como estagiária e, em dois ou três meses, ela começou a fazer parte do seu elenco.

Desde então, Anette começou a se aprofundar na dança, buscando fazer aulas com vários professores, tais como Victória Milanez, Cecy Frank, Charles Linhares, Roseli Rodrigues e Carlota Portela, dentre outros. Em 1995, criou sua própria companhia de dança denominada Anette Lubisco Cia de Dança e, até 2006, criou diversas obras coreográficas.

Quando a técnica corporal específica da dança jazz foi sistematizada, ela já era híbrida, possuía elementos característicos, porém cada professor/coreógrafo seguia a vertente com a qual mais se identificava, sendo assim até os dias atuais (JESUS; DANTAS, 2008). Nesse sentido, as criações de Anette são marcadas por códigos $^{2}$ de movimento e uma leitura musical diferenciada.

Esse estudo é de cunho qualitativo, tendo como aporte metodológico a história oral, que utiliza as entrevistas como principal fonte para a investigação, procurando compreendê-las de forma contextualizada. Segundo Alberti (2005) a história oral é um método de pesquisa que privilegia a realização de entrevistas com pessoas que participaram de ou testemunharam acontecimentos, conjunturas, visões de mundo, como forma de se aproximar do objeto de estudo.

Os procedimentos para realização e processamento das entrevistas foram desenvolvidos a partir do "Manual prático para esclarecimento de procedimentos básicos a serem realizados nas entrevistas", idealizado pela equipe do Projeto Garimpando Memórias do Centro de Memória do Esporte (CEME) da Escola de Educação Física (ESEF) da Universidade Federal do Rio Grande do Sul e as entrevistas realizadas nesse estudo fazem parte do conjunto de fontes desse projeto ${ }^{3}$.

O instrumento de coleta de informações adotado foi a entrevista semiestruturada. As entrevistas foram realizadas com Anette Lubisco e com três bailarinas que dançaram em sua Companhia de Dança. A escolha das três bailarinas ocorreu devido a sua participação na Cia. de Dança Anette Lubisco e por terem dançado ou participado do processo de criação da obra coreográfica selecionada para esse estudo ${ }^{4}$. As escolhidas são: Andrea Nedeff, Aline Nogueira Haas ${ }^{5}$ e Camila Arioli. As entrevistadas assinaram um termo de consentimento livre e esclarecido onde concordaram em revelar suas identidades para o registro histórico, pois seria uma perda não divulgar o nome delas. As entrevistas foram registradas em mídia digital (gravador portátil) e depois passaram por um processo no qual foram transformadas em documento escrito. Os dados das entrevistas foram analisados de maneira contextualizada e conectados a documentos dos acervos pessoais das entrevistadas.

As discussões teóricas deste estudo foram permeadas pelas ideias presentes em obras que abordam a temática de dança jazz (JESUS e DANTAS, 2008; HAAS et al, 2013); da história oral (ALBERTI, 2005; PESAVENTO, 2005) e de processo coreográfico (LOUPPE, 2012; NACHMANOVITCH, 1993; SMITH-AUTARD, 2010).

\section{Caminhos dos Processos de Criação de Anette Lubisco}

Anette Lubisco vê seu processo de criação como algo bem simples, na medida dos elementos que ela uti

\footnotetext{
1 Grupo de dança contemporânea fundado por Tony Petzhold nos anos 70.

2 Palavra utilizada pela coreógrafa para identificar movimentos que ela considera que expressem o que ela visualizou na criação.

3 Este protocolo foi aprovado pelo Comitê de Ética da UFRGS sob o número 2007710. As entrevistas encontra-se disponíveis no Repositório Digital da UFRGS: http://www.lume.ufrgs.br/handle/10183/40504

4 Foi escolhida, pela própria coreógrafa, uma de suas obras coreográficas para ser analisada nesse estudo: "Jezebel". Essa escolha se deu, para que se possa compreender como ocorreu o processo de criação dessa coreografia, considerada pela coreógrafa uma das suas obras mais relevantes.

Orientadora e sujeito de pesquisa desse estudo. Constatamos que era essencial sua participação, pois esteve presente desde a primeira proposta coreográfica realizada por Anette Lubisco, por isso o registro de suas memórias e experiências são importantes para o trabalho.
} 
liza, que é o corpo dos outros. Porém, esse processo é complexo de ser entendido por apresentar códigos que, muitas vezes, são de difícil compreensão para o bailarino que executa seus movimentos. Esse processo gira em torno de movimentos com diversos códigos que vão se criando: "No primeiro momento deve ocorrer a identificação no corpo do bailarino, para após fazer uma moldagem e finalmente reproduzir movimentos que já tem uma identidade corporal" (LUBISCO, 2013, p. 5). Ainda destaca: "Gosto de trabalhar com códigos, mas nada de espetacular. É simples. É um processo natural como ocorre em qualquer outra profissão” (LUBISCO, 2014, p. $5)$.

Ela considera o processo simples, porém difícil do corpo mostrá-lo ou representá-lo:

Trabalho com códigos e não é em qualquer corpo que ele se adapta. Exige inteligência, com habilidades complexas que devem ser treinadas. Por isso, inicialmente preciso desse corpo como molde para entender esse código que visualizo na minha mente. Cada bailarino carrega suas experiências em dança, e com isso, pode tornar meu código mais interessante e não deixo passar despercebido (LUBISCO, 2014).

A coreógrafa trabalha com a música e a forma. Segundo ela: "A primeira coisa que me move e provoca é a música. Gosto de estar ligada com músicas que tenham composições com mensagens que me identifico" (2013, p. 6). Então, inicialmente, ela faz pesquisas de músicas e, normalmente, os compositores escolhidos acabam se repetindo. Sendo estes: Tori Amos, Natalie Merchant, Lenine, Sarah Mclachlan e Zeca Baleiro. Anette escolhe esses artistas por identificação de letras, que muitas vezes falam como ela pensa e como ela vê o mundo. Ela ainda diz "gosto da melodia que me leva, me agrada, me move e eu vou junto com ela" (2013, p. 6).

Para Anette a forma é a representação do código, onde ela busca a identidade. Ela quer que o aluno/ bailarino entenda que precisa de processos, de corpo, de aula, de códigos de como se faz o seu movimento. $\mathrm{O}$ trabalho coreográfico de Anette Lubisco demanda que o bailarino faça aulas. Ela afirma: "hoje em dia acho que tem pouca gente fazendo aula, eu venho de um tempo que se fazia muita aula, se desejava mais, agora tudo é mais fácil, tem graduação é mais acessível” (2013, p. 6).

Segundo Jesus e Dantas (2008) a trajetória do bailarino e coreógrafo influencia fortemente em sua movimentação coreográfica. Por possuir uma variedade de estilos, existem diversas formas de coreografar a dança jazz e, principalmente, diversas dinâmicas de movimento. Nesse âmbito, é importante o bailarino ser eclético, ter experiência em outras técnicas e, até mesmo, com vários professores da dança jazz. Além disso, não basta saber a técnica, é necessário saber interpretar a coreografia, demonstrar sentimentos e emoções. A técnica não deve ser considerada a dança em si, pois cada indivíduo terá sua maneira de se movimentar.

A coreógrafa acredita que sua metodologia/estratégia de ensino mudou bastante da época que ela tinha a Anette Companhia de Dança: "Como tinha a mente lá na frente, eu pressupunha que a pessoa já sabia o que eu queria. E não era desta forma, pois teria que ir ensinando. Naquela época, eu não tinha esse refinamento" (2014, p. 3). Camila Arioli vê essa mudança: "Ela explica mais. Mesmo na ULBRA quando fui aluna dela, em 2005, ela dava aula de um jeito e mudou, ela foi evoluindo, unindo mais o teórico com o prático" (2014, p. 8). Andrea Nedeff fala sobre sua experiência inicial no Phoenix ${ }^{6}$ e após: "Eu dancei com ela quando ela estava começando a coreografar, e depois se passaram 10 anos e eu voltei a dançar com ela numa fase que ela já dominava muito mais o que ela estava fazendo" (2014, p. 6); e, deixa evidente o refinamento da coreógrafa quando afirma "então são duas fases bem diferentes, e com certeza agora está bem mais madura" (2014, p. 6). Aline Haas também percebe algumas mudanças: "quando ela entrou nesse processo de voltar a estudar de novo, a fazer especialização na PUC em dança e depois como professora na ULBRA, ela começou a repensar um pouco essa questão da forma de coreografar e de inserir o bailarino no processo" (2014, p. 10). Anette ainda destaca: "Muitas pessoas não se adaptavam ao meu jeito de trabalhar os processos de criação. Talvez não estivessem preparados para encarar a complexidade que propunha" $(2014$, p. 3) e acredita que "depois que entrei na academia (universidade), me aproximei de gente mais preparada, as coisas começaram a render para ambos os lados" (2014, p. 3).

Para Anette Lubisco o processo de criação é simples e didático:

Como artista, que tem no DNA criar, tem que ter naturalidade, humildade, simplicidade para compartilhar com os bailarinos uma ideia intensa que é sua. Eu vejo a dança como uma profissão, e o coreógrafo uma funcionalidade. É bem simples, é bem didático. Tem pessoas que fantasiam, fazem desta funcionalidade um fetiche (LUBISCO, 2014). 
Os atos criativos, incluindo a improvisação e a composição, devem ser formas de divertimento, exploração e desafios às hierarquias sociais. A mente criativa brinca com o que ama. Quando brincamos, nossas ações tomam caminhos inusitados, expandimos o próprio campo de ação, reorganizamos nossas capacidades e nossa verdadeira identidade (NACHMANOVITCH, 1993). Quando o autor traz o termo "brincar", não quer dizer que a obra não deve ter seriedade, mas sim que deve ser algo prazeroso e livre.

Podemos perceber que as bailarinas pouco colaboravam nos processos de criação da coreógrafa, um dos motivos era porque Anette coreografava compulsivamente e outro é porque elas não se consideravam boas criadoras. Como podemos observar na fala de Andrea Nedeff: "Eu não tenho perfil de coreógrafa, não gosto de colaborar, gosto de ser dirigida. Não tenho nenhuma vontade de criar coisas assim, na dança” (2014, p. 3) e ainda destaca que nesses poucos momentos de improvisação, os códigos eram tão orgânicos que acabavam parecendo coreografados "nesses raros momentos, a gente tinha tudo tão incorporado que acabava saindo assim como se fosse coreografado" (2014, p. 7). Percebemos este aspecto também na fala de Aline Haas: "Eu não me considero uma pessoa muito coreógrafa. E o tempo que eu dancei com a Anette ela não trabalhava muito com essa ideia que eu acho que ela está fazendo mais agora, que é o processo da criação do bailarino" (2014, p. 10). Camila destaca uma questão diferente, mas também fala que, em geral, tudo está pronto: "Mas quando é um solo o bailarino tem mais liberdade em alguns momentos, porque na hora de dançar a gente acaba se colocando mais. Então se tem alguma coisa que ela gosta mais, acaba modificando, mas são em detalhes" (2014, p. 4). Esse ponto se modificou nas suas aulas atuais, pois em algumas composições coreográficas os alunos improvisam em alguns momentos.

Sobre como acontece o processo de criação de Anette Lubisco, as três bailarinas trouxeram falas parecidas. Aline Haas diz: "ela estuda a sequência e a música e vem com tudo pronto. Ela começa trabalhando essa sequência em aula e depois ela leva pra uma coreografia eventual" (2014, p. 18). Andrea Nedeff fala: "ela começava a lançar as sequências em sala de aula, porque nós todas fazíamos aula juntas, e junto com as outras colegas, depois ela ia fisgando pra coreografia" (2014, p. 7) e ainda destaca "ela sempre partiu da ideia de laboratório" (2014, p. 7). E Camila aponta: "Sempre tem sequências da aula que ajudam pra dar uma base, faz as sequências na aula para já sair dançando, ela pega algum gesto, uma sequência pequena dali e cola com outra, vira o lado, troca as diagonais" (2014, p. 6).

Há momentos em que acontecem interações entre os bailarinos, como Aline traz na sua fala: "tem alguns momentos que tinha interação dos bailarinos que ela precisava construir junto, não tinha como ela imaginar muito sozinha como que aquilo iria acontecer" (2014, p. 18). Camila também destaca esse ponto: "os fluxos sempre são feitos na hora, no improviso, vai pegando e vai montando, ela já tem uma ideia pra onde quer ir, mas ela cria na hora" (2014, p. 6); e ainda a bailarina acrescenta: "Então no processo de criação têm essas duas coisas, o lado racional, ou seja, as coreografias que ela já formatou na aula e essa questão da espontaneidade que vai se ajustando com a energia das pessoas" (2014, p. 6). Andrea acredita que esse processo da Anette não acontecia apenas em relação com os bailarinos que estavam participando da obra: "Acho que na verdade era um processo de criação que ela se aproveitava de muitas coisas que estavam ao redor dela, e não só de nós" (2014, p. 7).

As bailarinas durante a entrevista apontam pontos que julgam marcantes nas obras coreográficas de Anette Lubisco. Aline Haas destaca: "a questão do uso da música é marcante, aliás, do não uso da música, ou seja, ela usa a música, mas ela usa uma parte da música que é muito difícil de entender” (2014, p. 16); e, sobre o movimento: "Ele pode ser muito feio em pessoas que não sabem executar, eu acho que para ela é muito difícil criar pra algumas pessoas. Ao mesmo tempo ele é dinâmico, ele é lento, mas ele é sensual e não clichê" (2014, p. 16). Quando Aline Haas fala em movimento "feio em pessoas que não sabem executar", podemos acrescentar o que Anette fala: "Por isso o bailarino precisa saber o meu código mais firmemente, porque vai dar mais clareza depois pra compor as peças" (2014, p. 5). Andrea Nedeff fala: "Uma coisa que é muito marcante nela é essa quantidade de movimentos diferentes que ela consegue criar" (2014, p. 6) e também comenta sobre a identificação: "tu precisa te identificar com esse jeito que ela tem de movimentar que é diferente" (2014, p. 6). E Camila traz o uso do gesto: "Os gestos inventados por ela, acho bem marcantes, quando penso nas coreografias eu lembro desses gestos” (2014, p. 5)

Duas bailarinas falam também sobre o enredo das coreografias e destacam que as obras coreográficas não possuíam estórias, mas que com certeza o público inventava a sua própria. Andrea Nedeff diz: "Na verdade eles faziam coreografias em cima das músicas e não tinha enredo" (2014, p. 5). E Camila Arioli fala: "Não 
tem uma estorinha literal. Tem aquela questão do olhar de quem está assistindo que normalmente monta uma estória, mas para os bailarinos não tem" (2014, p. 7). Anette fala sobre questão da dramaturgia em seus trabalhos, que se modificou com o seu amadurecimento: "Às vezes o próprio ballet traduzia a loucura da minha cabeça, não tinha uma racionalidade muito clara no trabalho porque eu ainda não tinha desenvolvido bem isso" (2014, p. 5); e, atualmente: "eu já vejo que dá pra criar uma dramaturgia se desprendendo um pouco do meu cérebro, mas utilizando o código" (2014, p. 6). Segundo Louppe (2012) a dança é a visão do mundo em si.

Anette Lubisco acrescenta sobre sua forma de criação:

Minhas criações são empíricas, baseadas nas minhas experiências de vida, nos questionamentos e observações que faço e na relação que mantenho com o mundo. No inicio eu criava muito, e colocava minha loucura nos meus processos que resultavam em códigos interessantes (LUBISCO, 2014).

No caso da dança, pensando em ferramentas, entendemos que o instrumento para criação de uma poética reside no próprio corpo. E, por pensamento, é um conjunto de ideias, pressupostos teóricos e representações que sustentam uma determinada visão de mundo (LOUPPE, 2012), ou seja, o coreógrafo coloca nas suas criações a forma como se relaciona com a dança e com o mundo.

Anette Lubisco cria suas obras coreográficas baseadas nas suas vivências e relaciona seu posicionamento em relação a sua visão de mundo, fazendo um estudo nos códigos e nos compositores que expressam suas concepções de maneira parecida com suas ideias.

Ao perguntar sobre os compositores e trilhas sonoras utilizadas pela coreógrafa, as três bailarinas citaram Natalie Merchant, Tori Amos, Zeca Baleiro e falam sobre a questão da inspiração nas letras de músicas. Camila Arioli diz: "ela não se baseia exatamente ao pé da letra, ela vai bem mais para o lado não racional. A Anette não é de falar tudo, fica claro sem precisar ser falado" (2014, p. 7). Aline Haas destaca: "o movimento dela tem muita relação com a música, mas não exatamente no tempo da música” (2014, p. 17).

Anette Lubisco fala que, além da trilha sonora, outras linguagens são consideradas importantes na sua obra coreográfica:

\footnotetext{
A trilha sonora é uma linguagem importante para mim, pois como falei antes, é a primeira coisa que me move. O figurino é uma consequência da criação, sempre usei tecidos que acompanhassem os movimentos e também são muito simples e básicos. Não gosto que o figurino interfira nos códigos. Porém, a luz tem importância e por isto considero a textura dos tecidos. (LUBISCO, 2014)
}

Além disso, destacamos que, durante sua trajetória, Anette aderiu a forma de registro dos seus processos coreográficos. Ela anota em um caderno toda a pesquisa que faz em cima da música e da forma, escreve suas criações e, atualmente, registra em vídeo como se desenrola esse processo nos corpos dos bailarinos. Para finalizar este item do texto, podemos sintetizar que o processo coreográfico de Anette Lubisco se baseia na linguagem jazz, tem forte influência da música, possui movimentações que exigem um preparo dos bailarinos, é feita com as ideias centrais da coreógrafa, desenvolvidas em aula, com pouca participação dos bailarinos (na época analisada), não tem como objetivo uma história literal mas deixar que o público entenda e complete os sentidos.

\section{Proposta Coreográfica “Jezebel”}

A coreografia "Jezebel” faz parte da obra coreográfica "Por Causa da Chuva” de 2006, que teve duas edições, porém "Jezebel” foi dançada apenas na segunda quando foi realizada uma remontagem do espetáculo. O elenco do espetáculo "Por Causa da Chuva" era: Aline Haas, Andrea Nedeff, Daniela Nobre, Fernanda Borges e Viviane Tremea. Andrea Nedeff fala na entrevista sobre o espetáculo: "o Por causa da chuva, ele foi muito em cima das letras das músicas" (2014, p. 5) e destaca "todo mundo ali se identificava com aquilo, eram situações muito fáceis da gente se identificar, era tudo muito feminino" (2014, p. 5). A obra era dividida em dois atos, o primeiro com músicas de Tori Amos e Natalie Merchant e o segundo com músicas de Zeca Baleiro, como podemos perceber na fala de Aline Haas: "Ela fez todo o Por causa da chuva com músicas dessas cantoras, o primeiro ato, e depois o segundo ato ela botou o Zeca Baleiro” (2014, p. 12). 
Na segunda versão da obra, havia um solo chamado "Vermelho", que antecedia a coreografia "Jezebel" e era dançado pela bailarina Aline Haas. Aline destaca esse solo como uma das coreografias mais marcantes dançadas por ela e comenta: "é um solo meio difícil de executar, mas é legal, bem legal" (p. 15, 2014). Enquanto o solo era dançado, as outras bailarinas entravam uma a uma como se estivessem sendo atraídas por ela, sentavam no chão e ficavam observando a solista com seus rostos hipnotizados. As coreografias dançadas antes da obra "Jezebel" já traziam os códigos que seriam mais explorados na obra. Esse solo é como se fosse um diálogo entre mulheres, uma confraternização muito sutil.

As bailarinas usaram vestidos vermelhos que marcavam bem os quadris, ocorrendo uma maior movimentação do tecido na parte inferior do figurino. A coreografia tem aproximadamente quatro minutos, iniciando com uma "corrente" humana no meio do palco, todas num grupo, entrelaçadas de alguma forma. Uma frase de movimentos é dançada duas vezes, a primeira vez é dançada em conjunto e a segunda vez é dançada individualmente. É perceptível a utilização de códigos que se repetem ao longo da coreografia, destaco o "infinito" e outro que também chama atenção é um código que as bailarinas denominaram de "chapéu". A coreografia é marcada por uma compulsão de movimentos e com expressões faciais fortes. O DVD 7 dessa proposta coreográfica foi disponibilizado pela coreógrafa, dessa forma foi possível fazer essas considerações mais detalhadas sobre a coreografia "Jezebel".

Assim como as outras obras coreográficas de Anette Lubisco, essa foi empírica. A música usada é de Natalie Merchant, uma cantora norte-americana, que iniciou a carreira em uma banda de rock chamada “10.000 Maniacs”. O nome da música é Jezebel e foi lançada em 1993, no álbum "Our Time in Eden” e a tradução da letra fala sobre o vínculo sagrado entre um homem e uma mulher, o casamento e a falta de amor que essa mulher carrega.

Anette Lubisco afirma que, na época dessa criação, estava cercada por mulheres que tinham personalidade forte como a da princesa Jezebel descrita na Bíblia, mas que algumas fizeram escolhas diferentes: "A Jezebel busca mostrar este desencanto das escolhas das mulheres. Mulheres que tinham tudo e pareciam não ter nada. E eu acho que isso é cultural. Então essa obra vem falar dessa minha maneira de ver a vida e da mulher contemporânea" (2014, p. 6) e acrescenta ainda "Naquele momento que eu criei era mais intenso esse movimento pra mim, porque eu convivia com sugestões de mulheres que não me agradavam muito”(2014, p. 9).

A figura Jezebel está associada à liderança, uma mulher determinada e independente, popularmente conhecida como sedutora e sem escrúpulos. Na Bíblia seus feitos encontram-se em 1 Reis capítulo 21, versículos 1-29 e sua morte é narrada em 2 Reis, capítulo 9, versículos 30-37. Casada com o Rei de Israel, Acabe, tinha domínio sobre seu reinado e o marido não ousava desobedecê-la. Religiosos julgam essa mulher como um espírito do mal e que seria o pior exemplo de esposa. Essa visão religiosa está associada a como a cultura se desenvolveu durante anos, na qual a mulher deveria ser passiva e respeitar o marido.

Anette Lubisco considera essa obra coreográfica como um marco e diz: "é um marco importante para, como mulher, pensar na transversalidade que ela tem que assumir. Às vezes, pode escolher uma vida infeliz, a mulher se naturaliza infeliz, casa com quem não quer, faz coisas pra agradar os outros" (2014, p. 5) e ainda acrescenta "Muitas optam mais pelo dinheiro do que pela felicidade" (2014, p. 6). Segundo Anette, Jezebel é uma mulher mais masculina, não falando em sexualidade, mas sim na forma de pensar e conduzir a vida. Então na coreografia, Anette buscou criar códigos que narrassem sutilmente essa ideia, onde o público poderia se identificar de acordo com o que pensa e sente.

A coreógrafa considera "Jezebel" como marco, pois acredita que foi quando atingiu o ápice da criação, não em termos de resultado, mas no qual o exercício de habilidade e complexidade de suas criações atingiu o ponto máximo. Se ela tivesse continuado nesse caminho pensa que se tornaria uma boa coreógrafa, porém naquele momento o foco foi ser professora acadêmica e, portanto, deixou de exercitar tão a fundo a função de criação artística. A partir de então, Anette criou coreografias, mais voltadas às sequências de sala de aula.

“Jezebel" traz um ar misterioso e transcreve a realidade em entrelinhas. É uma personagem que esconde algo e tem poder. Anette desenvolveu ao longo de sua trajetória uma habilidade de deixar "o dito, não dito", ela não precisa falar tudo, porém os bailarinos compreendem aonde ela quer chegar. A coreógrafa sempre assumiu suas escolhas mesmo sabendo que o caminho poderia ser difícil: "Sempre assumi que não queria filhos, que eu queria um casamento. Assumi ser coreógrafa mesmo não sendo considerada uma profissão; assumi os riscos destas escolhas" (2014, p. 6). 


\section{Considerações Finais}

Através desse estudo podemos considerar que as criações de Anette Lubisco são um processo empírico, baseado na sua visão de mundo e que a música e a forma são suas inspirações iniciais e a partir de então ela explora códigos que visualiza na sua mente nos corpos dos bailarinos. É importante ressaltar que esses bailarinos precisam de um treinamento, para que entendam essa técnica diferenciada. O criar para a coreógrafa é algo simples, essa facilidade sempre a acompanhou e por isso podemos falar que é um talento que foi se desenvolvendo durante sua trajetória. As três bailarinas entrevistadas, muitas vezes, trouxeram falas parecidas, principalmente quando o tema tratado foi o processo de criação. Todas destacaram que a coreógrafa cria com muita facilidade e apresenta todo o material pronto, ou seja, a sequência já realizada e a música escolhida. Em aula ela trabalha um módulo de aquecimento que desenvolveu ao longo da sua carreira, exercícios com códigos que normalmente são utilizados nas coreografias e, por fim, ela faz laboratórios, criando fragmentos coreográficos. Essa movimentação feita em aula, posteriormente, é usada em obras coreográficas que ela realiza com alunos que possuem sua linguagem mais desenvolvida/incorporada e estas são apresentadas para o público, na maioria das vezes dentro da Universidade.

Apesar das bailarinas apresentarem falas parecidas e por terem vivido algumas vezes os mesmos momentos, notamos que cada uma delas traz percepções diferentes. Por vezes algo é mais importante para uma, mais marcante para outra e nem tão significante para a terceira. Isso já era esperado, pois como Pesavento (2005) diz quando estudamos a história, as representações do passado não são engessadas como verdade, mas sim como uma versão. Cada pessoa recebe a informação e a interpreta como quer baseada nas suas experiências, nos seus anseios e nas suas sensações.

A obra coreográfica "Jezebel” escolhida para esse estudo é considerada um marco na vida de Anette Lubisco, ela acredita que essa criação foi o ápice do seu processo de criação e vê que esse momento era ideal para construir uma carreira mais aprofundada como coreógrafa. Porém, junto com esse momento, veio a oportunidade e a necessidade de se aprimorar como professora acadêmica e essa foi sua escolha. A dança faz parte de Anette Lubisco. Hoje em dia, ela trabalha na Universidade com dança e desenvolve pesquisas na linha dos estudos culturais, que se tornou algo muito importante na sua vida.

Consideramos, assim, que o trabalho de Anette Lubisco tem um papel importante na história e no desenvolvimento da dança jazz em Porto Alegre. Ela é uma das precursoras que continua trabalhando e dando aulas dessa técnica.

\section{Referências}

ALBERTI, Verena. Manual de história oral. 3.ed. Rio de Janeiro: FGV, 2005236 p.

ARIOLI, Camila. Entrevista com Camila Arioli. Projeto Garimpando Memórias. Porto Alegre: Centro de Memória do Esporte, Esef/Ufrgs, 2014.

BÍBLIA. Português. Bíblia sagrada. Tradução da Bíblia Reina Valera. Edição 1. Rio de Janeiro: Unipro Editora, 2009.

HAAS, Aline; DALMOLIN, Caroline; PORTO, Natália Athayde. Dança jazz em porto alegre: origens e evolução. Arquivos em movimento, Rio de Janeiro, v.9, n.1, p. 47-61, jan/jun2013.

HAAS, Aline. Entrevista com Aline Haas. Projeto Garimpando Memórias. Porto Alegre: Centro de Memória do Esporte, Esef/Ufrgs, 2014.

JESUS, Caroline Kummer; DANTAS, Mônica. Propostas coreográficas da dança jazz na cidade de Porto Alegre. Arquivos em Movimento, vol. 2, n. 8, jul-dez, 2008.

LOUPPE, Laurence. Poética da Dança Contemporânea. Portugal: Orfeu Negro, 2012. 
LUBISCO, Anette. Entrevista com Anette Lubisco I: Projeto Garimpando Memórias. Porto Alegre: Centro de Memória do Esporte, Esef/Ufrgs, 2013.

LUBISCO, Anette. Entrevista com Anette Lubisco II: Projeto Garimpando Memórias. Porto Alegre: Centro de Memória do Esporte, Esef/Ufrgs, 2014.

MIRANDA, Andrea Nedeff. Entrevista com Andrea Nedeff Miranda. Projeto Garimpando Memórias. Porto Alegre: Centro de Memória do Esporte, Esef/Ufrgs, 2014.

NACHMANOVITCH, Stephen. Ser criativo: O poder da improvisação na vida e na arte. 4. ed. São Paulo: Summus Editorial, 1993.

PESAVENTO, Sandra Jatahy. História \& história cultural. 2. ed. Belo Horizonte: Autêntica, 2005.

SMITH-AUTARD, Jacqueline. Dance Composition. 6. ed. Londres: Methuen Drama, 2010. 